\title{
Análise da incerteza experimental na determinacão da vida usando ensaio acelerado
}

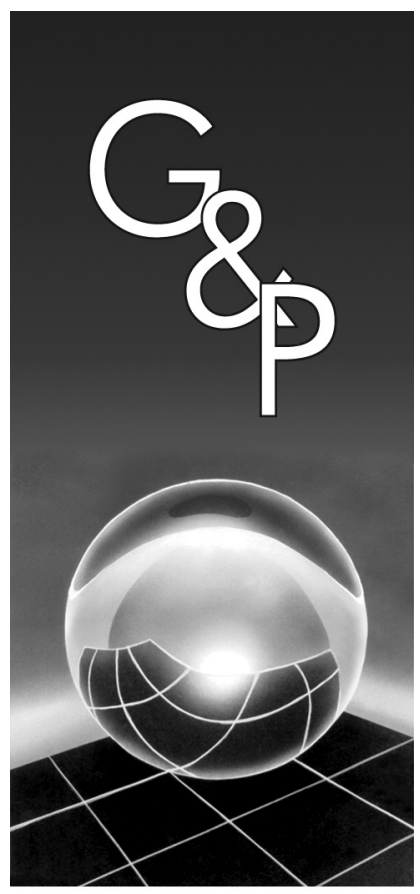

\author{
Alvaro José Abackerli \\ Maria Célia de Oliveira Papa \\ Paulo Augusto Cauchick Miguel \\ Pedro Luiz Sasseron
}

\section{Resumo}

Os estudos de confiabilidade e os ensaios acelerados de vida vêm sendo empregados por um grande número de empresas, principalmente devido a sua importância no desenvolvimento de produtos. Os ensaios acelerados consistem em colocar o produto em funcionamento para avaliar a sua probabilidade de falha ao longo do tempo, determinando-se a partir disso as chances dele sobreviver a um determinado tempo de uso, chamado de missão e, muitas vezes, associado aos prazos de garantia. Nos ensaios acelerados, as chamadas cargas de estresse são tratadas como variáveis cujos valores são nominalmente definidos. Deste modo, nos testes acelerados não são ponderadas as incertezas inerentes ao arranjo experimental, tampouco suas influências nos resultados obtidos por meio dos testes. Neste trabalho, métodos de Monte Carlo e dados reais de ensaios acelerados são usados para ilustrar os efeitos das incertezas na vida prevista de relés. Por meio deles, mostra-se também o impacto da incerteza experimental nas decisões gerenciais sobre a vida do produto, durante o seu desenvolvimento. Os resultados indicam que a incerteza presente nos ensaios acelerados pode ser significativa, mostrando, portanto, sua relevância tanto no desenvolvimento do produto quanto na definição de períodos de garantia.

Palavras-chave: Desenvolvimento de produto. Ensaio acelerado. Confiabilidade. Incerteza.

\section{Introdução}

Um dos requisitos essenciais no desenvolvimento de produtos são os estudos de confiabilidade (TAN, 2003), que vêm sendo empregados por um grande número de empresas. Por isso, a confiabilidade deve ser vista como parte da estratégia empresarial (MADU, 2005), capaz de gerar impactos relevantes na qualidade dos produtos que não pode ser alcançada sem que haja confiabilidade (MADU, 1999).

A confiabilidade $R(t)$ pode ser entendida como a probabilidade de um componente ou sistema sobreviver a uma missão com duração $t_{0}$ sob determinadas condições de uso (KENETT; ZACKS, 1998). Matematicamente, a função $R(t)$ pode ser escrita como apresentada na Equação 1, sendo $t_{0}$ a missão contada a partir do início da vida do produto. $R(t)$ é válida para as condições dadas de uso $C_{0}$.

$$
R(t)=P\left(t>t_{0}\right)
$$

Em outras palavras, a confiabilidade caracteriza as chances do produto ainda estar em funcionamento ao término de uma missão realizada no intervalo $\left[0, t_{0}\right]$. Sob o enfoque do desenvolvimento do produto, esta informação é usada para determinar, com uma dada confiança, o percentual de falhas em períodos específicos, a exemplo do período de garantia. Isso permite decisões qualificadas sobre questões estratégicas como os estoques de peças de reposição, a estrutura de serviços pós-venda e até as próprias condições normais de uso do produto para as quais se faz a cobertura em garantia. Neste contexto, é comum estabelecer o tempo necessário para que um percentual dos produtos falhe, digamos $10 \%$, que caracteriza a chamada vida típica $B_{x}=10 \%$ ou $B_{10}$. Em síntese, essa quantia de produtos que retornam em garantia é usada para estabelecer os limites aceitáveis de custeio em garantia pelo fabricante, representando por isso uma questão estratégica dentro do empreendimento.

Para cálculo dos custos totais $K_{T}$ decorrentes da garantia, podem-se adotar modelos que o decompõe em parcelas unitárias $K_{i}$ proveniente da logística, de fatores 
administrativos, de custos de mão de obra, além dos custos de peças, sendo cada uma dessas parcelas formuladas em função do tempo, na forma dada pela Equação 2 (PALEROSI, 2002).

$$
K_{i}(t)=(1-R(t)) \sum_{1}^{n} K_{i}
$$

A Equação 2 apresenta que na medida em que a confiabilidade $R(t)$ varia com o uso do produto, seu custo de garantia também se modifica, possibilitando estabelecer com uma dada confiança o aporte necessário de recursos para um volume de produção específico (PALEROSI, 2002). Isso explicita a importância da disponibilidade de boas estimativas de vida e da alta confiabilidade na avaliação das metas de projeto, em estágios ainda incipientes do desenvolvimento de produtos, mesmo frente aos pequenos períodos disponíveis entre o projeto e o lançamento de um novo produto (HAHN; MEEKER; DOGANAKSOY, 2003).

$\mathrm{Na}$ indústria de máquinas ferramentas, contexto do presente estudo, além dos requisitos acima descritos, relativos à garantia, o mercado consumidor impõe atualmente requisitos severos relativos à disponibilidade $\mathrm{e}$ mantenabilidade (US DEPARTMENT OF DEFENSE, 1997). Tais requisitos impactam diretamente no chamado custo de ciclo de vida (LCC - Life-cycle cost) ou custo estendido, o qual é dependente da vida e da confiabilidade de componentes críticos. Isso ocorre porque os baixos custos de ciclo de vida geram produtos mais atrativos ao mercado e mínimo suporte pós-venda, além de serviço ótimo ao consumidor (MARKESET; KUMAR, 2003), o que torna a determinação da vida de componentes críticos um fator estratégico no sucesso do produto, seja pela realidade do mercado pós-venda ou pelo tempo disponível para seu lançamento (time to market).

Contudo, apesar das suas potencialidades e do papel estratégico de $R(t)$, para que a vida ou missão $t_{0}$ seja determinada, é preciso validá-la por meio de testes, que envolvem a medição do intervalo de tempo $t_{0}$ em que o sistema funciona até a falha.

Pelo fato de relés serem componentes importantes, usados no acionamento de diversos subsistemas críticos de máquinas ferramentas, além de representantes típicos da importante família de elementos binários que integram diversos equipamentos industriais para os quais a confiabilidade é fator preponderante, neste trabalho, investiga-se o efeito das incertezas da variável de estresse nas previsões de confiabilidade obtidas por meio de ensaios acelerados destes componentes.

Para fundamentar teoricamente esta investigação, segue uma síntese dos principais conceitos ligados ao problema estudado, o detalhamento das condições experimentais usadas para a determinação da vida, o procedimento de simulação proposto e finalmente os resultados e sua discussão. Para fins de formalização metodológica, a pesquisa aqui discutida é caracterizada como teórico-experimental, tendo em vista que formula uma proposição teórica para análise e simulação não paramétrica de dados de ensaios acelerados, para a qual são utilizados dados experimentais reais obtidos por meio de ensaio acelerado.

\section{0 ensaio acelerado de vida}

Vassiliou e Mettas (2002) relatam que, em muitos casos, a obtenção de medidas de vida sob condições normais de funcionamento do produto é difícil, devido a fatores como a longa vida útil dos produtos ou o curto tempo disponível para os ensaios entre a concepção e o lançamento do produto, razão pela qual são executados os ensaios acelerados. Por isso, os ensaios acelerados caracterizam uma classe de testes cujo objetivo é abreviar o tempo necessário para obtenção de dados de vida do produto, podendo ser executados de duas formas: por meio do uso contínuo ou da aceleração pela aplicação de estresse (VASSILIOU; METTAS, 2002). Na primeira forma, produtos que não funcionam continuamente são assim operados nas condições nominais de uso $C_{0}$ até que a falha ocorra, acelerando-se deste modo a sua falha. Na segunda, a condição de uso $C_{0}$ é excedida em variáveis que interferem na vida, gerando-se as condições de estresse $C_{i}>C_{0}$ que fazem o produto falhar mais rápido.

$\mathrm{Na}$ execução de ensaios acelerados, a variável de estresse é determinada e ajustada em um valor nominal por meio de medições e da configuração física de componentes de ensaio. Por exemplo, no caso de relés, a variável de estresse utilizada é a corrente elétrica, expressa em amperes (A), que deve ser ajustada por meio da montagem de componentes elétricos apropriados no banco de ensaio. Os dados obtidos nestes ensaios são extrapolados para as condições normais de uso, empregando os denominados modelos de relacionamento vida-estresse (NELSON, 2004). A Figura 1 a seguir ilustra esse conceito. Nelas podem ser vistas as curvas correspondentes aos modelos de relacionamento clássicos de Eyring, Arrhenius e potência inversa (NELSON, 2004), que são usados em vários produtos para representar diferentes mecanismos de falha e projeções de vida.

A Figura 1 exemplifica cargas de estresse $C_{i}$ definidas em torno de 9,2, 11,6 e 15,0 A (Amperes), além da previsão da vida nas condições normais de uso $C_{0}$ de 5,0 A, segundo os diferentes modelos de relacionamento. Como será visto a seguir, o modelo ideal adotado para a investigação de relés aqui discutida é o modelo da potência inversa. Na Figura 1, os pontos circulares sobre as cargas de 9,2, 11,6 e 15,0 A representam os diferentes valores de vida, obtidos quando amostras aleatórias do relé foram ensaiadas nos diferentes níveis de estresse $C_{i}$. 


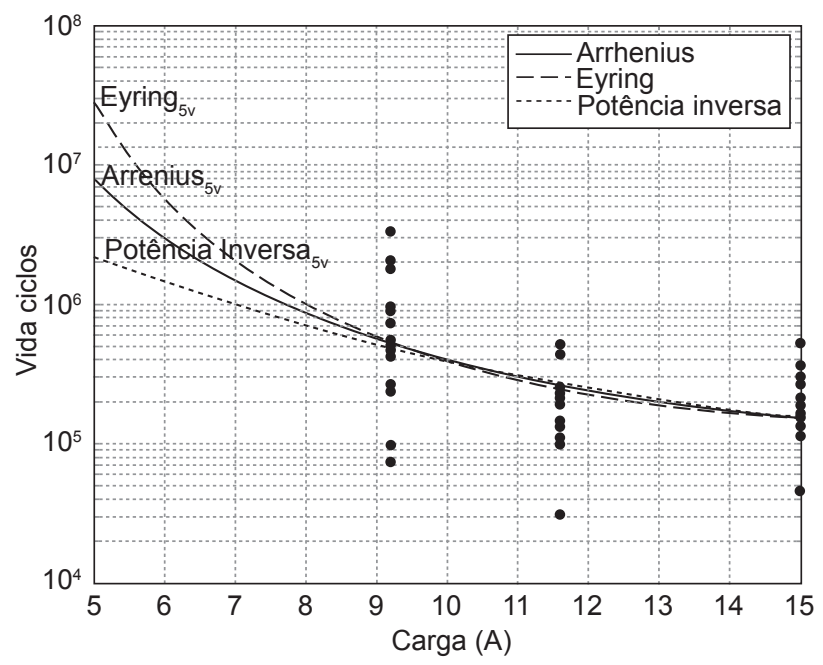

Figura 1. Conceitos de ensaio acelerado e transposição.

Deste procedimento é importante destacar que, devido às incertezas de medição (ISO, 1995), em um experimento real não se consegue ajustar a variável de estresse num valor absolutamente exato e constante durante todo o ensaio, fazendo com que o estresse efetivamente aplicado no produto não seja idêntico àquele nominalmente definido para o experimento. Além disso, as condições não controladas e sempre presentes em experimentos podem provocar variações da carga durante o ensaio, fazendo com que a variação da vida observada nas amostras não seja somente devida ao seu comportamento natural, mas também à variação do próprio experimento. Essas influências, causadoras de variação, são aqui denominadas incertezas experimentais.

\section{0 ensaio acelerado convencional aplicado no teste de relés}

Para efetuar a previsão da vida por meio de ensaios acelerados, a primeira etapa consiste em determinar a distribuição de probabilidade que modela os tempos de falha em cada nível de estresse $C_{i}$ usado no ensaio. Essas distribuições são funções de probabilidade que expressam a relação entre o nível de estresse e o tempo de vida do produto. Dentre as diversas distribuições de probabilidade existentes, a log-Normal é aqui discutida por ser a idealmente indicada para modelar as falhas dos relés no presente estudo (SASSERON, 2005). A distribuição log-Normal modela uma variável aleatória $t^{\prime}$ com distribuição Normal (Gaussiana), tal que $t^{\prime}=\log (t)$ e $t$ é a vida efetivamente medida no produto por meio dos testes. Assim, se $t^{\prime}$ segue uma distribuição Normal, dizemos que $t$ segue uma distribuição log-Normal, e sua função de densidade de probabilidade é dada pela Equação 3.

$$
\begin{aligned}
& f(t)=\frac{1}{t \sqrt{2 \pi \sigma}} e^{-\frac{1}{2 \sigma^{2}} \log (t-\mu)^{2}} \\
& \text { para }-\infty<\mu<+\infty \text { e } \sigma>0
\end{aligned}
$$

A segunda etapa consiste em utilizar esta distribuição (Equação 3), calculada nas condições de estresse $C_{i}$, no processo de extrapolação feito por meio do modelo de relacionamento vida-estresse. Investigações prévias mostram que o modelo de potência inversa é adequado para representar o mecanismo de falha estudado em relés eletromecânicos (SASSERON, 2005), cuja expressão geral é dada na Equação 4 e sua forma linearizada na Equação 5. Nelas, $\tau(V)$ é a vida nominal de interesse, $V$ é o valor do estresse e os parâmetros $\gamma$ e $K$ modelam características da vida do produto. Fundamentalmente, este modelo é usado para componentes que se degradam devido à tensão ou corrente elétrica, tensão mecânica, vibrações, choques, pressão, etc.

$$
\begin{gathered}
\tau(V)=\frac{K}{V^{\gamma}} \\
\ln (\tau)=\ln (K)-\gamma \ln (V)
\end{gathered}
$$

Em produtos modelados pela distribuição log-Normal, a vida mediana pode ser caracterizada como uma função inversa do estresse. Nestes casos, se a distribuição da vida é log-Normal para qualquer nível de estresse, se o desvio padrão $\sigma$ da vida logarítmica é constante e independente de $V$, a vida mediana pode ser calculada como apresenta a Equação 6 (NELSON, 2004).

$$
\tau_{.50}(V)=\frac{10^{\ln (K)}}{V^{\gamma}}
$$

A terceira e última etapa consiste em utilizar a distribuição de vida extrapolada para as condições normais de uso $C_{0}$ para determinar a vida típica de interesse, como, por exemplo, a vida mediana apresentada Equação 6.

Se a análise de interesse focaliza na incerteza experimental, mas não envolve censuras, uma primeira alternativa para a solução do problema envolveria o uso modelos linearizados na forma $y=a+b x$, em que $a=\ln (K)$ e $b=\gamma, \operatorname{com} x=\ln (V)$, Equação 5, seguido pelo cálculo dos parâmetros por meio do método dos mínimos quadrados (FORBES, 1989; PRESS et al., 1992) e ponderando os erros na variável independente conforme proposto por Press et al. (1992) e apresentado na Equação 7.

$$
\chi^{2}(a, b)=\sum_{i=1}^{N} \frac{\left(y_{i}-a-b x_{i}\right)^{2}}{\sigma_{y_{i}}^{2}+b^{2} \sigma_{x_{i}}^{2}}
$$

Na Equação $7 \sigma_{x_{i}}$ e $\sigma_{y_{i}}$ são, respectivamente, os desvios padrão da variável independente (estresse) e dependente (vida), compondo o que se chama variância ponderada $1 / w_{i}$. A solução acima pode ser aplicada desde que a hipótese de Normalidade de resíduos possa ser sufi- 
cientemente mantida (OREAR, 1982) e as variâncias sejam suficientemente constantes e independentes de $V$, conforme requerido pela linearização do modelo de relacionamento. Tais condições não são verificadas no problema em discussão, particularmente pela presença de censuras nos níveis mais baixos de estresse aplicado aos relés.

\subsection{Proposta para a ponderação da incerteza experimental}

Frente à presença de censuras nos resultados dos ensaios acelerados aqui discutidos e à clara impossibilidade do uso do método dos mínimos quadrados, como o acima discutido, buscou-se uma alternativa que tanto permitisse o tratamento das censuras quanto dispensasse suposições teóricas fortes acerca das distribuições que modelam os tempos de falha.

Como alternativa de análise optou-se pelo uso do estimador não paramétrico de Kaplan-Meier $\hat{\mathrm{S}}_{K M}$ (KENETT; ZACKS, 1998), conforme dado pela Equação 8, que dispensa suposições acerca da natureza ou da forma da distribuição populacional (WALPOLE; MYERS, 1993).

$$
\hat{S}_{K M}=\prod_{t_{i}<t_{0}} \frac{r\left(t_{i}\right)-d\left(t_{i}\right)}{r\left(t_{i}\right)}
$$

Na Equação $8, r\left(t_{i}\right)$ representa o número de produtos que sobreviveram pelo menos até o tempo $t_{i}, d\left(t_{i}\right)$ é o número de elementos que falharam no tempo $t_{i}$ e $t_{0}$ é a missão para a qual se calcula a confiabilidade. A Figura 2 ilustra o estimador de Kaplan-Meier calculado para a amostra ilustrada na Figura 1 com estresse para 9,2 A.

A partir desta informação calcula-se a vida $B_{X}$ de interesse, fazendo $R(t)=1-X / 100 \operatorname{com} X$ expresso em porcentagem e extraindo do gráfico o valor da vida $B_{X}$ correspondente.

Com as confiabilidades $R(t)$ calculadas não parametricamente e para cada nível de estresse aplicado no ensaio, portanto independentemente da distribuição, geram-se três tempos de vida para cada valor $B_{X}$ de interesse. Cabe enfatizar que nesta abordagem já se elimina o problema das censuras uma vez que os valores de $B_{X}$ as ponderam por terem sido obtidos a partir de estimadores de Kaplan-Meier, aplicados a cada nível de estresse.

Usando os valores de $B_{X}$ correspondentes às cargas de estresse de 9,2, 11,6 e 15,0 A, toma-se o modelo de relacionamento discutido (Equação 5) e o método dos mínimos quadrados para calcular a distribuição do estimador de vida nas condições normais de uso. Ou seja, tomam-se três pares $V_{i}, B_{X i}$ já isentos de censuras e independentes das distribuições de falhas para estimar os dois parâmetros $a=\ln (K)$ e $b=\gamma$ do modelo dado pela Equação 5.

A Figura 3a ilustra o esquema geral adotado na simulação do problema e mostra inicialmente os valores de

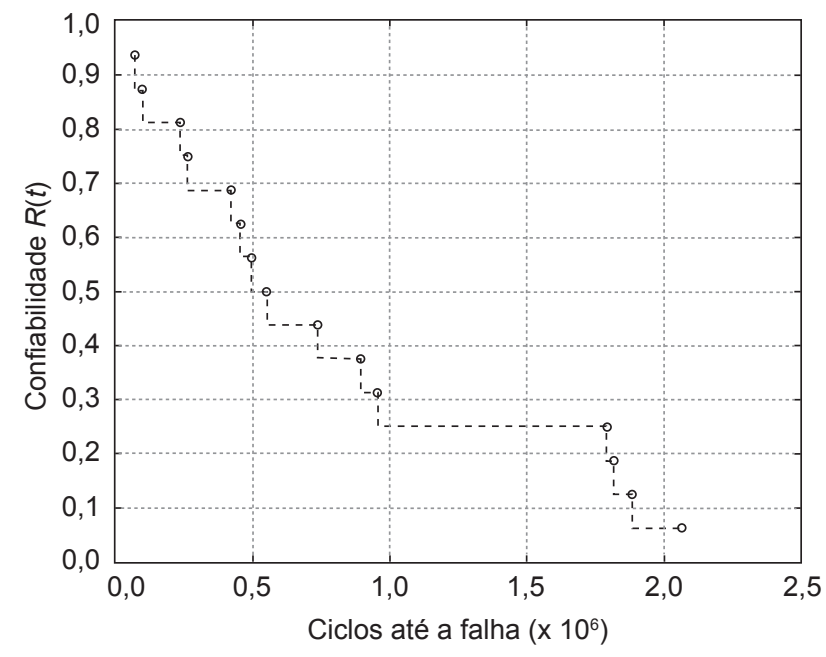

Figura 2. Estimador de Kaplan-Meier.
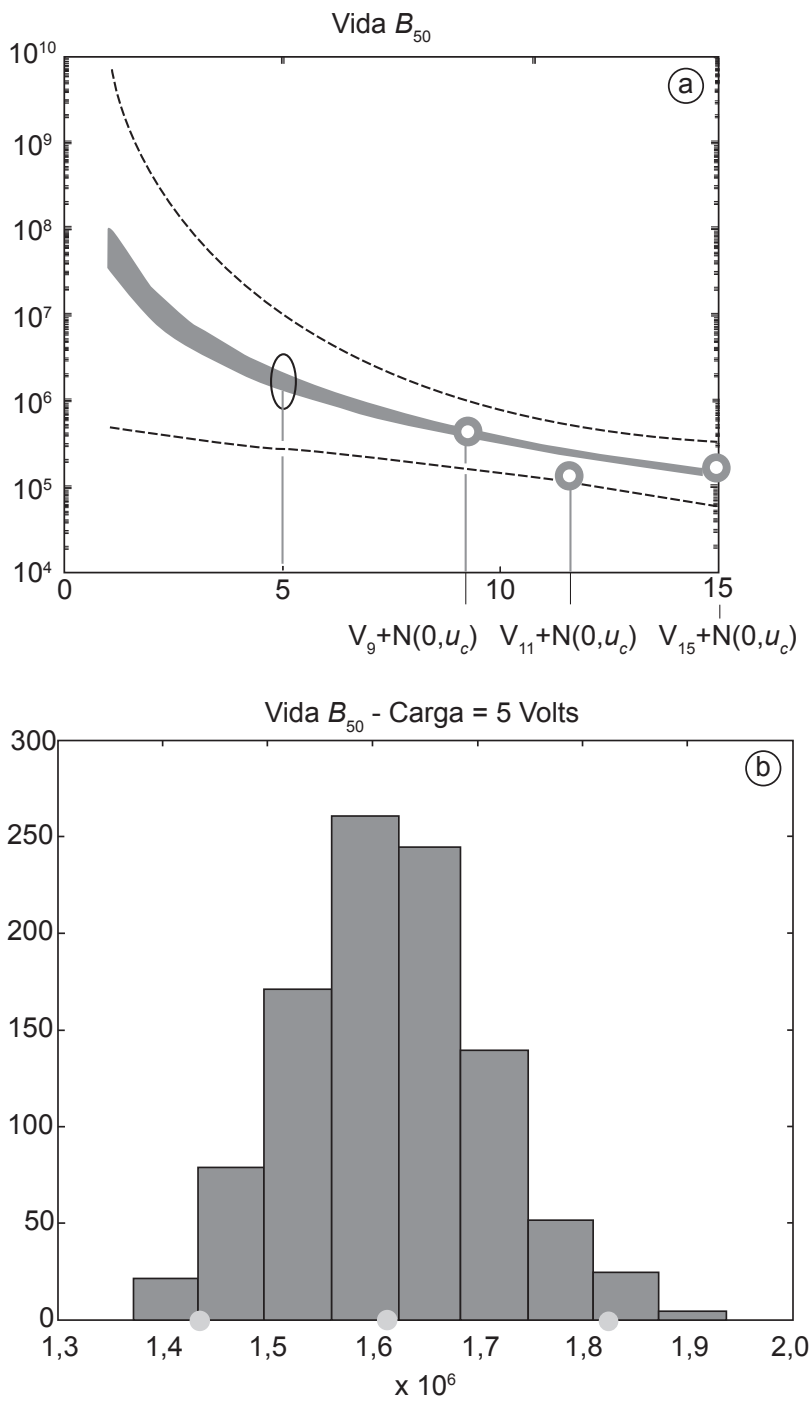

Figura 3. Esquema geral de solução. a) modelo da potência inversa, aplicado às vidas típicas $B_{50} ;$ e b) distribuição da vida típica $C_{0}$ na condição nominal de interesse. 
$B_{50}$ (pontos circulares) calculados por Kaplan-Meier para cada um dos níveis de estresse $V$ discutidos, quais sejam, $9,2,11,6$ e 15,0 A.

Se a incerteza da variável de estresse é desconsiderada, os valores de $B_{50}$ calculados para cada nível de estresse geram em conjunto uma única projeção de vida na condição de interesse, como ilustrado na Figura 1 para os diferentes modelos de relacionamento. A esta projeção única podemse acrescentar os limites de confiança $95 \%$, como também ilustrados pelas linhas tracejadas na Figura 3a.

Para ponderar o efeito da incerteza em cada nível de estresse utilizou-se da simulação de Monte Carlo (ver MOONEY, 1997). Assim, a proposta do presente trabalho considera o procedimento de Monte Carlo já adaptado, a seguir, para o problema de interesse:

a) especifica-se a pseudopopulação para representar a incerteza de interesse;

b) geram-se amostras da pseudopopulação selecionada;

c) influenciam-se os dados experimentais reais com as amostras da incerteza;

d) aplica-se o modelo de relacionamento escolhido;

e) obtém-se o estimador da vida na condição interesse;

f) repetem-se os passos de b até e para gerar uma grande amostra do estimador; e

g) calculam-se as estatísticas de ordem de interesse para o estimador.

Ainda na Figura 3b, o histograma representa a distribuição do estimador de $B_{50}$ obtida por meio dos procedimentos acima. Os pontos sobre o seu eixo horizontal mostram a mediana e os limites $95 \%$ calculados por meio do passo $\mathrm{g}$ do procedimento.

$\mathrm{Na}$ Figura 3, foi usada uma incerteza combinada $u_{c}=0,01$ A (ISO, 1995) assumindo uma distribuição Normal para a incerteza na definição da condição de ensaio $C_{i}$ em cada nível de estresse. Ou seja, a pseudopopulação da incerteza de que trata o passo b (acima) define uma condição $C_{i} \cong N\left(\mu_{C_{i}}, u_{c}\right)$, da qual são feitas diversas reamostragens para influenciar os três valores nominais de estresse, conforme ilustrados na Figura $3 \mathrm{a}$.

Aqui, três destaques são necessários em relação ao método de solução proposto: o significado da incerteza experimental, cuja influência é analisada; o uso do estimador $B_{X}$, obtido pelo método não paramétrico de Kaplan-Meier; e o uso das estatísticas de ordem para a caracterização do estimador na condição de interesse.

Com relação à incerteza, é importante observar que ela é aqui interpretada estritamente como definida pelo guia de expressão de incertezas (ISO, 1995), que a considera como a medida da dúvida na grandeza física em função de todos os fatores que a influenciam. Neste sentido, ela representa todos os valores atribuíveis ao mensurando (estresse), dentro das condições estabelecidas, para os quais se disponha de informações de previsão. Neste contexto, a incerteza aqui representa todas as dúvidas na definição da carga de estresse aplicada ao produto, compreendendo também a variação desta carga em função da execução do próprio experimento. Esta observação é relevante porque nem sempre é possível estabelecer condições perfeitamente controladas nos ensaios vida, seja por questões técnicas ou financeiras, fazendo com que a estimativa de vida obtida seja influenciada também pela incerteza do experimento e não somente pela variabilidade inerente à qualidade do produto, que é o objeto de investigação nestes testes. Resumindo, trata-se da simulação dos possíveis valores que a carga de estresse pode assumir em função dos condicionantes do experimento e não somente dos valores medidos da carga durante $o$ ensaio, já que ela permanece nominalmente constante de acordo com o ajuste do próprio experimento.

A estimação não paramétrica dos valores da vida $B_{X}$ pelo método Kaplan-Meier permite a inclusão dos dados censurados, tipicamente presentes em dados de ensaios de vida, como acontece no estudo dos relés ora discutido. O cálculo de um estimador $B_{X}$ para cada valor de estresse resolve as restrições de Normalidade de resíduos impostas pelos métodos de regressão. Além disso, o comportamento do produto é sintetizado em um único estimador $B_{X}$ para cada valor de estresse, que depois é extrapolado para as condições normais de uso $C_{0}$. Essa síntese tende a minimizar os efeitos da incerteza no valor extrapolado de vida, mas permite a análise do experimento usando a simulação de Monte Carlo, que não poderia ser feita por métodos convencionais se fosse necessário manter as suposições teóricas acerca da distribuição populacional de falhas dos relés.

Na mesma lógica de argumentação, se tem o uso de estatísticas de ordem para a caracterização da distribuição do próprio estimador $B_{X}$ na condição $C_{0}$ de interesse. Isso não somente é compatível com as estimativas não paramétricas do estimador $B_{X}$, mas também, e principalmente, permite o uso da mesma abordagem para todos os níveis de estresse usados, sem a necessidade de caracterização individual da distribuição do estimador nas diversas condições $C_{0}$ de interesse.

O cálculo da variação do estimador $B_{X}$ é executado conforme a Equação 9, usando os quantis estimados na distribuição de vida do produto nas condições $C_{0}$.

$$
\Delta B_{X}=100 \frac{Q_{97,5}\left(B_{X}\right)-Q_{2,5}\left(B_{X}\right)}{Q_{50}\left(B_{X}\right)}
$$

Na Equação 9, a variação $\Delta B_{X}$ analisada do estimador é calculada como porcentagem, obtida do quociente entre a diferença dos quantis 97,5 e 2,5\% pelo valor mediano $Q_{0.50}$ estimado para cada $B_{X}$. Conforme já citado, na Figura $3 \mathrm{~b}$ esses quantis e valor mediano estão representados pelos pontos sobre o eixo das abscissas do histograma. 
Para avaliar o efeito da variação da incerteza no valor $B_{X}$ típico, previsto nas condições de interesse $C_{0}$, calculouse a variação $\Delta B_{X}$ conforme apresentado na Equação 10.

$$
\Delta \breve{B}_{X}=100 \frac{\max \left\{Q_{50}\left(B_{X}\right)\right\}-\min \left\{Q_{50}\left(B_{X}\right)\right\}}{Q_{50}\left(B_{X}\right)}
$$

Na Equação $10, \Delta \breve{B}_{X}$ representa a variação percentual observada no valor mediano $Q_{50}$ calculado para cada $B_{X}$. $O$ processo de simulação discutido e implementado em plataforma MatLab ${ }^{\circledR}$ é ilustrado na Figura 4.

Aqui é importante destacar dois aspectos relevantes da metodologia discutida, uma inerente à sua versatilidade $\mathrm{e}$ outra à sua utilidade no desenvolvimento do produto.

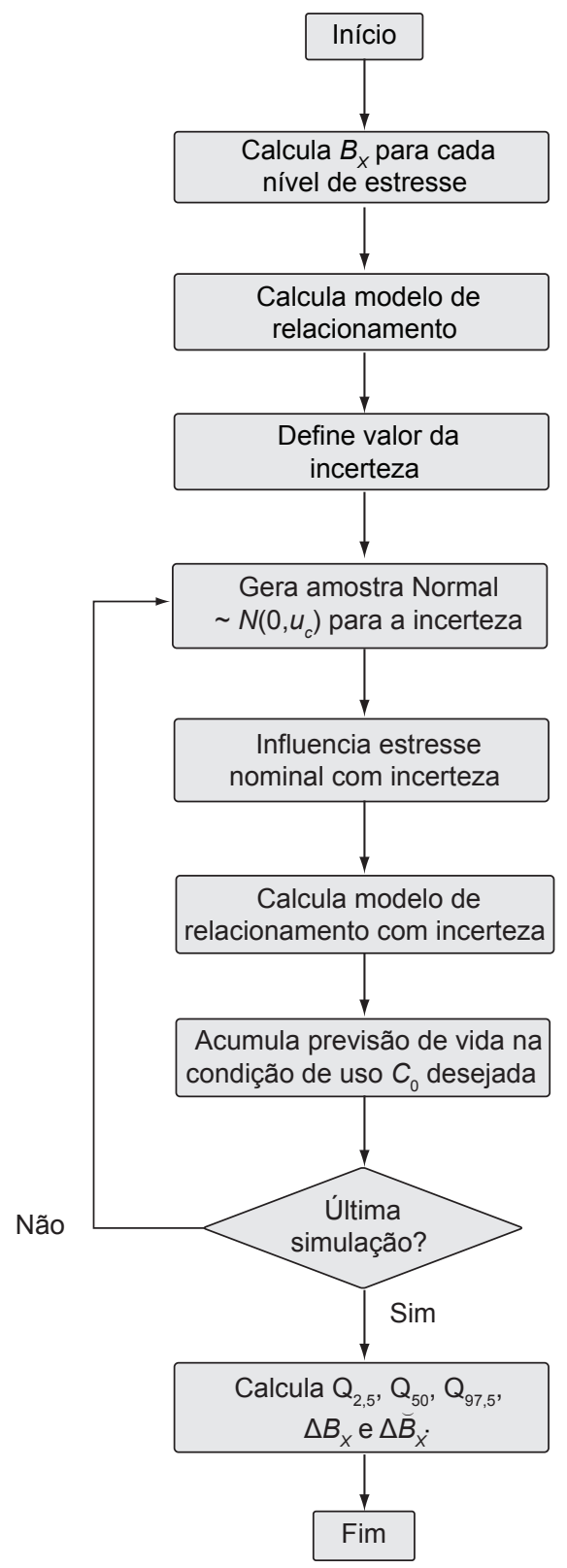

Figura 4. Simulação de Monte Carlo para a influência da incerteza.
No que se refere à versatilidade, trata-se de um processo de simulação usado em conjunto com dados reais de vida obtidos por meio de ensaios acelerados. Por isso, pode-se tanto calcular a variação da estimativa de vida em função das condições experimentais disponíveis quanto projetar ensaios que atendam às expectativas originárias de outros requisitos intrínsecos ao desenvolvimento do produto.

Quanto à sua utilidade, destaca-se inicialmente que a metodologia proposta disponibiliza informações relevantes sobre as estimativas de vida não disponíveis por outros métodos, já que pondera incertezas experimentais que não são consideradas em procedimentos convencionais de acelerados. Além. Além disso, as influências simuladas na vida útil prevista do produto podem ser usadas diretamente na correção dos prazos de garantia, indo ao encontro dos condicionantes estratégicos de cada projeto específico.

\section{0 ensaio experimental dos relés}

Para a implementação da análise aqui discutida os dados referentes ao ensaio acelerado de vida de três lotes de 16 relés, foram coletados em pesquisa prévia (SASSERON, 2005) e organizados conforme apresenta a Tabela 1.

Para coleta destas informações, os lotes aleatórios de relés foram instalados em um banco de ensaios especialmente projetado para este fim, submetendo-os a ciclos sucessivos de liga-desliga até sua falha.

Por meio de um controlador lógico programável (CLP), o chaveamento de cargas resistivas foi monitorado para detecção da aplicação efetiva da corrente de estresse dos relés sob teste. O mesmo controlador lógico

Tabela 1. Resultados de teste acelerado de vida de relés (adaptado de SASSERON, 2005).

\begin{tabular}{|c|c|c|c|c|c|c|}
\hline \multirow[b]{3}{*}{ Amostra } & \multicolumn{6}{|c|}{ Níveis de estresse $C_{i}>C_{0}$} \\
\hline & \multicolumn{2}{|c|}{$9,2 \mathrm{~A}$} & \multicolumn{2}{|c|}{$11,6 \mathrm{~A}$} & \multicolumn{2}{|c|}{$15,0 \mathrm{~A}$} \\
\hline & Ciclos & Evento & Ciclos & Evento & Ciclos & Evento \\
\hline 1 & 73352 & $\mathrm{f}$ & 31085 & $\mathrm{f}$ & 45588 & $\mathrm{f}$ \\
\hline 2 & 98033 & $\mathrm{f}$ & 98888 & $\mathrm{f}$ & 111632 & $\mathrm{f}$ \\
\hline 3 & 236320 & $\mathrm{f}$ & 109381 & $\mathrm{f}$ & 113205 & $\mathrm{f}$ \\
\hline 4 & 264699 & $\mathrm{f}$ & 131948 & $\mathrm{f}$ & 132499 & $\mathrm{f}$ \\
\hline 5 & 420441 & $\mathrm{f}$ & 132251 & $\mathrm{f}$ & 153180 & $\mathrm{f}$ \\
\hline 6 & 455503 & $\mathrm{f}$ & 136459 & $\mathrm{f}$ & 163699 & $\mathrm{f}$ \\
\hline 7 & 495202 & $\mathrm{f}$ & 138240 & $\mathrm{f}$ & 164788 & $\mathrm{f}$ \\
\hline 8 & 550119 & $\mathrm{f}$ & 143818 & $\mathrm{f}$ & 179237 & $\mathrm{f}$ \\
\hline 9 & 733991 & $\mathrm{f}$ & 191223 & $\mathrm{f}$ & 204592 & $\mathrm{f}$ \\
\hline 10 & 894067 & $\mathrm{f}$ & 208244 & $\mathrm{f}$ & 211918 & $\mathrm{f}$ \\
\hline 11 & 953393 & $\mathrm{f}$ & 209839 & $\mathrm{f}$ & 216590 & $\mathrm{f}$ \\
\hline 12 & 1793409 & $\mathrm{f}$ & 229059 & $\mathrm{f}$ & 251962 & $\mathrm{f}$ \\
\hline 13 & 1817479 & $\mathrm{f}$ & 254377 & $\mathrm{f}$ & 266807 & $\mathrm{f}$ \\
\hline 14 & 1882756 & $\mathrm{f}$ & 433524 & $\mathrm{f}$ & 300019 & $\mathrm{f}$ \\
\hline 15 & 2064540 & $\mathrm{f}$ & 500092 & $\mathrm{f}$ & 367829 & $\mathrm{f}$ \\
\hline 16 & 3309823 & $\mathrm{c}$ & 522573 & $\mathrm{f}$ & 526826 & $\mathrm{f}$ \\
\hline
\end{tabular}


programável executou a contagem do número de ciclos até que a falha de cada relé foi observada, cujos valores são apresentados na Tabela 1. No momento da falha, o número de ciclos acumulados do relé foi indelevelmente registrado para posterior análise.

Durante este procedimento, o ambiente de ensaio teve sua temperatura de $55{ }^{\circ} \mathrm{C}$ monitorada e controlada nas condições limites especificadas pelo fabricante do relé. Destaca-se ainda que para todos os relés considerou-se o mesmo modo de falha, segundo detecção automática efetuada pelo próprio CLP.

Na Tabela 1, a coluna da esquerda (Amostra) contém a ordem das amostras inspecionadas quando cada número de operações (Ciclos) foi atingido. Nas colunas subseqüientes, podem ser vistos os números de ciclos para cada um dos três níveis de estresse de corrente elétrica usados nos testes, quais sejam; 9,2, 11,6 e 15,0 A. Ao lado observam-se os códigos "f" ou "c" que indicam, respectivamente, falhas ou censura, esta última representando que o relé foi retirado do teste no número de ciclos indicado sem apresentar a falha investigada. Mais detalhes acerca dos conceitos sobre falha e censura podem ser encontrados em O'Connor, Newton e Bromley (2004).

\subsection{Planejamento e simulação da incerteza}

Conforme discutido, para demonstrar a influência da incerteza, os dados experimentais reais apresentados na Tabela 1 foram inicialmente utilizados para determinar a confiabilidade por meio do estimador de Kaplan-Meier. A Figura 2 já ilustrou a curva de confiabilidade para a carga de 9,2 A. O mesmo ocorre na Figura 5 para as cargas de 11,6 e $15,0 \mathrm{~A}$.

No planejamento da simulação, três aspectos devem ser considerados; os valores de vida $B_{X}$ que representem aspectos relevantes da vida do produto, os valores teóricos da incerteza que mimetizam condições reais de ensaios acelerados, e os valores da carga nas condições normais de uso $C_{0}$ nas quais se avalia o efeito da incerteza.

Os valores de vida $B_{X}$ de $10,25,50,75$ e $90 \%$ foram escolhidos dentro de limites passíveis de análise pela simulação proposta. Os valores de $B_{10}$ e $B_{50}$ foram escolhidos por serem usados regulamente na estimação de prazos de garantia e da vida típica de produtos. Os demais valores foram selecionados para permitir uma grande cobertura na análise pretendida, mesmo não sendo típicos em problemas reais de confiabilidade.

Conforme propõe o fluxograma da Figura 4, para a simulação são necessários valores estimados de incerteza experimental $u_{c}$ em cada condição de estresse $C_{i}$, para as quais foram escolhidos os valores de $0,01,0,03$, $0,05,0,10,0,15,0,20,0,25$ e 0,30 A. A Tabela 2 mostra a representatividade percentual destas incertezas nos valores nominais definidos para os três níveis de estresse utilizados nos testes.
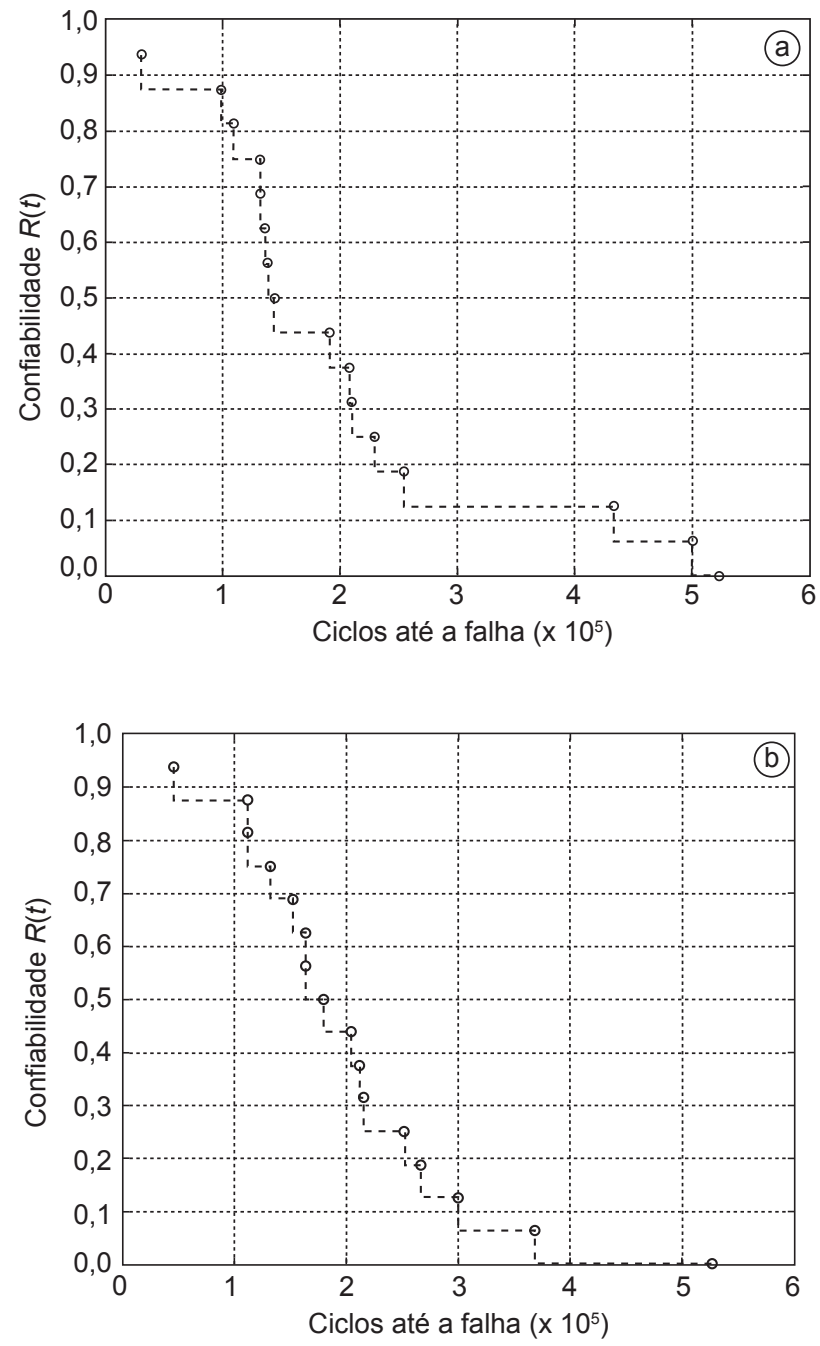

Figura 5. Estimador de Kaplan-Meier. a) carga de 11,6 A; e b) carga de $15,0 \mathrm{~A}$.

Tabela 2. Contribuição percentual da incerteza experimental.

\begin{tabular}{ccccccccc}
\hline Estresse (A) & \multicolumn{8}{c}{ Incerteza experimental $\boldsymbol{u}_{\boldsymbol{c}}(\mathbf{A})$} \\
\cline { 2 - 9 } & $\mathbf{0 , 0 1}$ & $\mathbf{0 , 0 3}$ & $\mathbf{0 , 0 5}$ & $\mathbf{0 , 1 0}$ & $\mathbf{0 , 1 5}$ & $\mathbf{0 , 2 0}$ & $\mathbf{0 , 2 5}$ & $\mathbf{0 , 3 0}$ \\
\hline 9,2 & 0,11 & 0,33 & 0,54 & 1,09 & 1,63 & 2,17 & 2,72 & 3,26 \\
11,6 & 0,09 & 0,26 & 0,43 & 0,86 & 1,29 & 1,72 & 2,16 & 2,59 \\
15,0 & 0,07 & 0,20 & 0,33 & 0,67 & 1,00 & 1,33 & 1,67 & 2,00 \\
\hline
\end{tabular}

Da tabela pode-se observar inicialmente a existência de contribuições percentuais de cerca de $3 \%$, que correspondem a valores típicos de incertezas encontradas nos meios regulares de medição presentes no chão-de-fábrica. Portanto, elas correspondem a medições usuais, compatíveis com um ensaio real de vida de produto, como os aqui discutidos.

Do ponto de vista prático, cabe observar que os dados da Tabela 2 geram incertezas expandidas $U$ (ISO, 1995) seis vezes superiores aos valores de $u_{c}$ mostrados, chegando a uma contribuição percentual em torno de $20 \%$ 
em relação aos valores nominais de estresse. Isso não é um percentual exagerado para a incerteza expandida, se considerado que nela estão inclusas todas as causas de variação na carga de estresse durante o teste acelerado e não somente aquelas devidas ao processo de medição das próprias cargas. Se fossem somente relativas à medição física das cargas, incertezas expandidas da ordem de $20 \%$ seriam por demais grosseiras para ensaios de vida de produtos.

Por outro lado, as menores influências percentuais de aproximadamente $0,1 \%$ (Tabela 2) correspondem a valores demasiadamente bons para condições de chãode-fábrica, podendo, contudo, ser obtidos em ambiente de laboratório com condições bem controladas para o teste do produto. Deste modo representam valores observáveis em condições práticas otimizadas de ensaios acelerados.

Estes valores simulados de incerteza implicam na seguinte lógica dedutiva sobre os resultados da simulação discutida a seguir: se a relevância da incerteza na previsão de vida for verificada nas maiores influências percentuais (Tabela 2), ela será importante no desenvolvimento do produto, pois simula condições típicas de chão-de-fábrica. Por outro lado, se relevância for verificada também nas menores influências percentuais da incerteza, ela representará uma situação ainda mais crítica no desenvolvimento do produto, pois será uma condição atipicamente boa para ensaios acelerados.

Finalmente, trabalhou-se nos níveis de estresse para caracterizar as condições normais de uso $C_{0}$ considerando três possibilidades: 5,0, 7,0 e 1,0 A. A primeira condição de 5,0 A representa o valor nominal de corrente de carga recomendado pelo fabricante do relé testado, sendo portanto uma condição normal de uso inerente ao componente investigado. A corrente de 7,0 A representa um ponto intermediário entre 5,0 e 9,2 A, que foi o primeiro nível de estresse aplicado ao componente, sendo por isso de interesse na análise da variação simulada. A última condição $(1,0 \mathrm{~A})$ exemplifica uma extrapolação para uma condição normal $C_{0}$ realmente distante da menor condição de estresse aplicada, permitindo ilustrar o efeito da incerteza em situação extrema. É importante destacar que este último caso $(1,0 \mathrm{~A})$ é relevante porque os testes acelerados são realizados para abreviar significativamente o tempo de teste, levando naturalmente ao distanciamento das condições normais $C_{0}$ das condições $C_{i}$ que caracterizam o estresse, como se verifica neste caso.

A combinação destas condições, envolvendo as vidas típicas $B_{X}$ de interesse, os valores de incerteza $u_{c}$ e as condições normais $C_{0}$ para a extrapolação geraram um total de 120 combinações de simulação. Para cada combinação 1000 amostras Normais $N\left(0, u_{c}\right)$ foram geradas para a incerteza, permitindo construir a distribuição do estimador nas condições $C_{0}$ de interesse, como já ilustrado na Figura $3 b$ e discutido nos itens a seguir.

\section{Resultados experimentais e discussões}

As simulações foram executadas como apresentado anteriormente com resultados organizados na Tabela 3.

A Tabela 3 apresenta valores de vida típica $B_{X}$, expressos em ciclos até a falha, obtidos na simulação quando uma incerteza $u_{c}$ de $0,15 \mathrm{~A}$ foi utilizada. Os dados apresentados representam 15 das 120 combinações de simulação executadas. Em cada linha da tabela pode ser visto o estimador $B_{X}$ de interesse, dado pelo seu valor mediano $Q_{50}\left(B_{X}\right)$, seguido dos quantis $Q_{2.5}\left(B_{X}\right)$ e $Q_{97,5}\left(B_{X}\right)$ anteriormente discutidos. Na última coluna, verifica-se a variação $\Delta B_{X}$ (Equação 9). Portanto, cada

Tabela 3. Síntese parcial de resultados da simulação com $u_{c}=0,15 \mathrm{~A}$.

\begin{tabular}{|c|c|c|c|c|c|}
\hline$C_{0}(\mathrm{~A})$ & $B_{X}(\%)$ & $Q_{50}\left(B_{X}\right)$ & $Q_{97,5}\left(B_{X}\right)$ & $Q_{2,5}\left(B_{X}\right)$ & $\Delta B_{X}(\%)$ \\
\hline \multirow[t]{5}{*}{1} & 10 & 93262 & 100948 & 85623 & 16,4 \\
\hline & 25 & 5038049 & 6698331 & 3874205 & 56,1 \\
\hline & 50 & 58631280 & 96754394 & 37886716 & 100,4 \\
\hline & 75 & 7228810410 & 16022232491 & 3743233638 & 169,9 \\
\hline & 90 & 4856116759 & 9567867409 & 2565301326 & 144,2 \\
\hline \multirow[t]{5}{*}{5} & 10 & 85316 & 87668 & 82834 & 5,7 \\
\hline & 25 & 540998 & 600702 & 491612 & 20,2 \\
\hline & 50 & 1611304 & 1936816 & 1368260 & 35,3 \\
\hline & 75 & 13166145 & 17557691 & 10315953 & 55,0 \\
\hline & 90 & 14385547 & 18574612 & 11398915 & 49,9 \\
\hline \multirow[t]{5}{*}{7} & 10 & 83735 & 85144 & 82258 & 3,4 \\
\hline & 25 & 339297 & 363753 & 318723 & 13,3 \\
\hline & 50 & 761431 & 857041 & 686307 & 22,4 \\
\hline & 75 & 3518021 & 4233807 & 3013333 & 34,7 \\
\hline & 90 & 4263924 & 5049863 & 3653212 & 32,8 \\
\hline
\end{tabular}


linha da tabela corresponde à síntese de 1000 reamostragens de Monte Carlo.

A Figura 6 traz os histogramas das vidas $B_{50}$ obtidas por reamostragem da incerteza nas condições normais $C_{0}$ de 1,0 A e 5,0 A.

Para a análise das variações percentuais $\Delta B_{X}$ da vida mediana típica, nas condições $C_{0}$ de interesse e como função da incerteza experimental, os valores de $\Delta B_{X}$ (Equação 9) apresentados na última coluna da Tabela 3 foram organizados em conjunto, como mostra a Tabela 4.

O primeiro aspecto relevante a ser observado, que condiz com as expectativas, é o aumento da variação percentual
$\Delta B_{X}$ com o aumento da incerteza experimental. Os dados revelam que esta variação pode ser relevante mesmo para incertezas experimentais pequenas, o que corrobora com a preocupação motivadora desta investigação.

Verifica-se, por exemplo, o crescimento da variação percentual com a incerteza para qualquer vida típica $B_{X}$, independente da condição normal $C_{0}$ na qual se queira realizar a previsão de vida com os dados obtidos dos ensaios acelerados.

Também, como o esperado, observa-se que a variação percentual aumenta com o aumento da diferença entre o valor da corrente que caracteriza as condições $C_{0}$ e $C_{i}$, mostrando que o problema investigado tende a se agravar
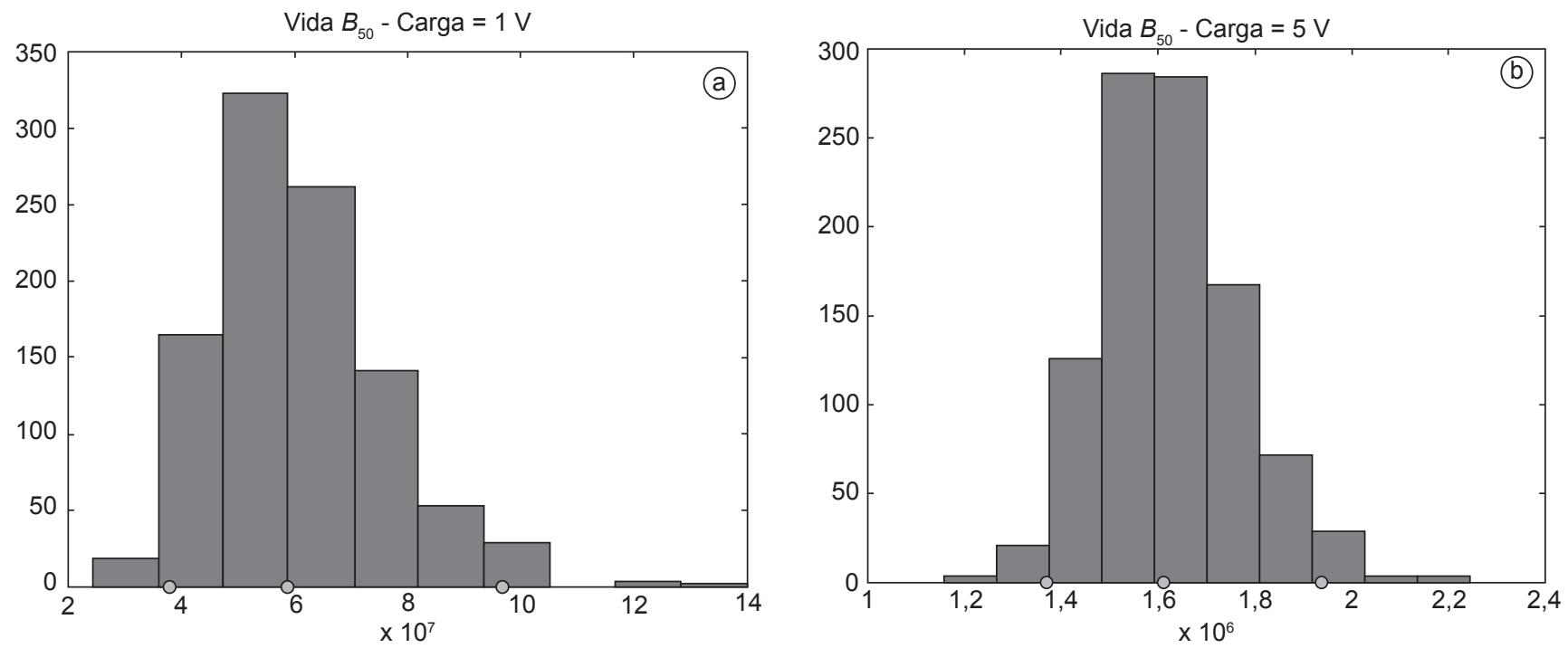

Figura 6. Histogramas de $B_{50}$. a) corrente de 1,0 A; e b) corrente de 5,0 A.

Tabela 4. Análise conjunta da variação percentual $\Delta B_{X}(\%)$.

\begin{tabular}{|c|c|c|c|c|c|c|c|c|c|}
\hline \multirow[t]{2}{*}{$C_{0}(\mathrm{~A})$} & \multirow[t]{2}{*}{$B_{X}(\%)$} & \multicolumn{8}{|c|}{ Incerteza experimental $u_{c}(\mathrm{~A})$} \\
\hline & & $\mathbf{0 , 0 1}$ & $\mathbf{0 , 0 3}$ & $\mathbf{0 , 0 5}$ & $\mathbf{0 , 1 0}$ & 0,15 & 0,20 & 0,25 & $\mathbf{0 , 3 0}$ \\
\hline \multirow[t]{5}{*}{1} & 10 & 1,0 & 3,2 & 5,3 & 11,3 & 16,4 & 21,5 & 26,6 & 32,1 \\
\hline & 25 & 3,7 & 11,3 & 18,3 & 37,2 & 56,1 & 75,8 & 106,3 & 134,1 \\
\hline & 50 & 6,8 & 19,3 & 31,9 & 66,5 & 100,4 & 137,3 & 193,6 & 247,3 \\
\hline & 75 & 11,0 & 32,4 & 52,9 & 104,2 & 169,9 & 297,8 & 392,4 & 552,0 \\
\hline & 90 & 9,3 & 26,5 & 47,4 & 93,9 & 144,2 & 253,9 & 293,1 & 426,7 \\
\hline \multirow[t]{6}{*}{5} & 10 & 0,4 & 1,1 & 1,9 & 3,9 & 5,7 & 7,4 & 9,2 & 11,1 \\
\hline & 25 & 1,4 & 4,2 & 6,7 & 13,5 & 20,2 & 26,6 & 36,9 & 44,8 \\
\hline & 50 & 2,5 & 7,2 & 11,6 & 23,9 & 35,3 & 46,6 & 60,9 & 73,4 \\
\hline & 75 & 4,0 & 11,9 & 19,1 & 37,4 & 55,0 & 83,7 & 102,6 & 126,4 \\
\hline & 90 & 3,4 & 9,9 & 17,6 & 34,3 & 49,9 & 74,1 & 87,6 & 108,1 \\
\hline & 10 & 0,2 & 0,7 & 1,1 & 2,4 & 3,4 & 4,5 & 5,6 & 6,7 \\
\hline \multirow[t]{4}{*}{7} & 25 & 0,9 & 2,7 & 4,4 & 8,6 & 13,3 & 17,0 & 23,5 & 28,7 \\
\hline & 50 & 1,6 & 4,5 & 7,4 & 15,4 & 22,4 & 30,3 & 38,9 & 46,1 \\
\hline & 75 & 2,6 & 7,7 & 12,4 & 24,4 & 34,7 & 52,4 & 63,2 & 76,0 \\
\hline & 90 & 2,2 & 6,4 & 11,5 & 22,5 & 32,8 & 46,1 & 56,3 & 67,1 \\
\hline
\end{tabular}


em aplicações em que se busque afastar o nível de estresse $C_{i}$ usado no teste das condições normais de uso $C_{0}$. Vêemse, por exemplo, variações de 247 e $32 \%$ na estimativa de $B_{50}$ e $B_{10}$ quando a incerteza é $0,30 \mathrm{~A}$. Essa incerteza não é um valor exagerado para $u_{c}$ no contexto discutido.

Não tão esperado, porém também importante, é o aumento da variação percentual $\Delta B_{X}$ com o aumento da vida $B_{X}$ de interesse. Por exemplo, as variações observadas na previsão de $B_{75}$ e $B_{90}$ são invariavelmente superiores àquelas verificadas para $B_{25}$ e $B_{10}$, independente da condição $C_{0}$ de interesse.

É importante notar que, mesmo para valores de incertezas tão pequenos quanto $0,01 \mathrm{~A}$, a variação percentual pode chegar a $1,6 \%$ na estimativa da vida típica $B_{50}$, corrente de 7,0 A, que demonstra a relevância do problema mesmo em condições altamente favoráveis de ensaio. Obviamente, nestas boas condições, a variação diminui para $0,2 \%$ na estimativa de $B_{10}$, que favorece algumas aplicações destes ensaios na determinação de prazos de garantia. Em outras palavras, se incertezas tão pequenas quanto $0,2 \%$ da carga de estresse pudessem ser sempre adotadas como limite em ensaios regulares de produtos, os ensaios acelerados poderiam ser utilizados sem grandes preocupações com as incertezas da carga quando a vida $B_{10}$ fosse de interesse para a determinação dos prazos de garantia e assistência técnica de produtos.

É importante notar ainda que a condição nominal $C_{0}$ com 7,0 A já é bastante próxima das condições aceleradas $C_{i}$ e representa uma condição de teste que otimiza a precisão da previsão de vida (NELSON, 2004). Também nela a influência é relevante quando os níveis de incerteza presentes nos ensaios são os típicos verificados no chãode-fábrica.

Para uma visão da tendência deste processo, os resultados são sistematizados na Figura 7.

Além da variação já discutida, analisaram-se também o efeito da variação da incerteza de ensaio no valor de vida típica, prevista nas condições $C_{0}$ e contida nos catálogos de componentes como os relés, conforme apresentado na síntese de resultados na Tabela 5. Naquela tabela, $\Delta \breve{B}_{X}$ representa a variação percentual do estimador mediano $Q_{50}$ de cada vida $B_{X}$, calculada nas condições $C_{0}$ (Equação 10). Nela pode ser observado, por exemplo, o crescimento progressivo da variação percentual $\Delta \breve{B}_{X}$ até a vida $B_{75}$, com a posterior queda desta influência na vida $B_{90}$ simulada. O mesmo comportamento pode ser visto na Figura 8 abaixo e já estava presente na Tabela 3.

Das Figuras 7 e 8 pode ser observado que a variação $\Delta \vec{B}_{X}$ causada pela incerteza no valor mediano $Q_{50}\left(B_{X}\right)$ é proporcionalmente pequena se comparada à variação dos valores individuais simulados que geram $\Delta B_{X}$. Para clareza da importância desta afirmação é importante reforçar aqui a diferença conceitual já discutida entre as duas medidas de variação propostas, $\Delta \breve{B}_{X}$ e $\Delta B_{X}$.

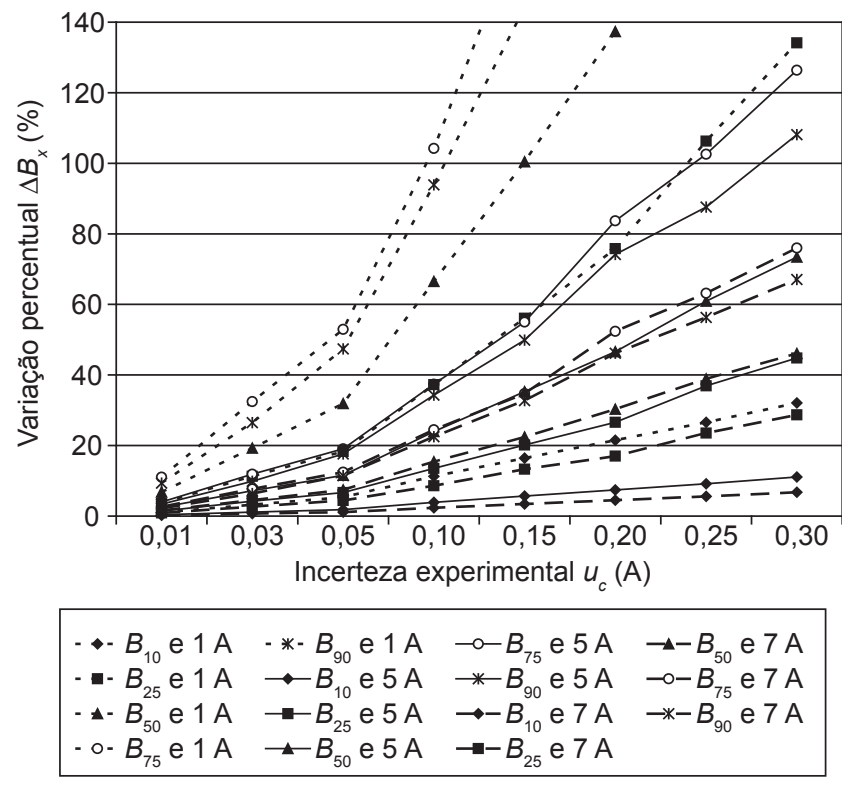

Figura 7. Variação percentual $\Delta B_{X}$.

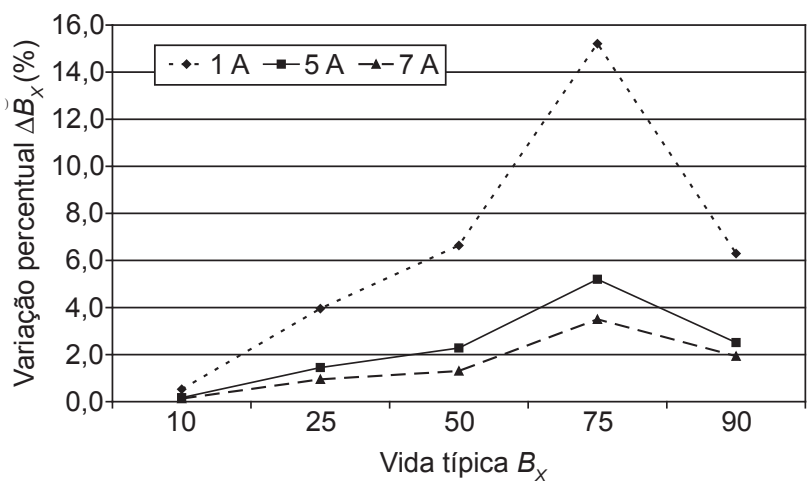

Figura 8. Variação percentual $\Delta \breve{B}_{X}$.

A medida $\Delta \breve{B}_{X}$ corresponde à variação do estimador mediano, cujos valores são apresentados nas linhas da Tabela 5, quando os diferentes valores de incerteza foram usados na simulação. Ou seja, trata-se da variação do ponto central de histogramas como os ilustrados nas Figuras 6a e 6 b, cujos valores estão grifados na Tabela 5 .

Já a medida $\Delta B_{X}$ representa a variação observada entre os valores que integram estes histogramas, em função também das incertezas, correspondendo, portanto à medida da variação de todos os possíveis valores que um determinado valor de $B_{X}$ poderia assumir nas condições de interesse $C_{0}$, devido às incertezas experimentais. Isso porque, conforme já discutido, a incerteza no valor extrapolado para as condições $C_{0}$ mede possibilidades de resultados e não valores causados por erros mensuráveis por meio de instrumentos regulares de medição.

Assim dizendo, pode-se afirmar que os grandes valores observados de $\Delta B_{X}$ indicam a relevância do problema 
Tabela 5. Análise conjunta da variação percentual do valor da vida mediana típica $Q_{50}\left(B_{X}\right)$.

\begin{tabular}{|c|c|c|c|c|c|c|c|c|c|c|}
\hline \multirow[t]{2}{*}{$C_{0}(\mathrm{~A})$} & \multirow[t]{2}{*}{$B_{X}(\%)$} & \multicolumn{8}{|c|}{ Incerteza experimental $u_{c}(\mathrm{~A})$} & \multirow[b]{2}{*}{$\Delta \breve{B}_{X}(\%)$} \\
\hline & & $\mathbf{0 , 0 1}$ & $\mathbf{0 , 0 3}$ & 0,05 & $\mathbf{0 , 1 0}$ & 0,15 & $\mathbf{0 , 2 0}$ & 0,25 & $\mathbf{0 , 3 0}$ & \\
\hline \multirow[t]{5}{*}{1} & 10 & 93456 & 93484 & 93491 & 93499 & 93262 & 93584 & 93093 & 93160 & 0,5 \\
\hline & 25 & 5085816 & 5077712 & 5080578 & 5054231 & 5038049 & 5052119 & 4992067 & 4886191 & 4,0 \\
\hline & 50 & 59349324 & 59143463 & 59200240 & 58440314 & $\mathbf{5 8 6 3 1 2 8 0}$ & 58410293 & 56580039 & 55463525 & 6,6 \\
\hline & 75 & 7506508839 & 7485015756 & 7469220252 & 7440200476 & 7228810410 & 7110999960 & 7102327342 & 6391172310 & 15,2 \\
\hline & 90 & 4840591200 & 4831238571 & 4834487674 & 4793414076 & 4856116759 & 4657557208 & 4553386509 & 4731228317 & 6,3 \\
\hline \multirow[t]{5}{*}{5} & 10 & 85373 & 85383 & 85386 & 85389 & 85316 & 85405 & 85259 & 85261 & 0,2 \\
\hline & 25 & 543070 & 542910 & 542722 & 541460 & 540998 & 541057 & 539108 & 535245 & 1,4 \\
\hline & 50 & 1620750 & 1618824 & 1618872 & 1613091 & 1611304 & 1614003 & 1593143 & 1583951 & 2,3 \\
\hline & 75 & 13319713 & 13308099 & 13300179 & 13298241 & 13166145 & 13148830 & 13096091 & 12632014 & 5,2 \\
\hline & 90 & 14374737 & 14368710 & 14363621 & 14325206 & 14385547 & 14134710 & 14025762 & 14284622 & 2,5 \\
\hline \multirow[t]{5}{*}{7} & 10 & 83773 & 83779 & 83780 & 83787 & 83735 & 83786 & 83708 & 83679 & 0,1 \\
\hline & 25 & 340229 & 340125 & 340007 & 339363 & 339297 & 339343 & 338367 & 337019 & 0,9 \\
\hline & 50 & 763539 & 763130 & 762873 & 761587 & 761431 & 760553 & 755853 & 753604 & 1,3 \\
\hline & 75 & 3543216 & 3540508 & 3537755 & 3540267 & 3518021 & 3513236 & 3496042 & 3419779 & 3,5 \\
\hline & 90 & 4259037 & 4257602 & 4257763 & 4251960 & 4263924 & 4221229 & 4181687 & 4239683 & 1,9 \\
\hline
\end{tabular}

investigado na determinação da vida típica de produtos por meio de testes acelerados, mesmo em condições favoráveis de ensaio. Do mesmo contexto se pode afirmar que os pequenos valores de $\Delta \breve{B}_{X}$ denunciam a pequena variação de $Q_{50}$. Como conseqüência, pequenos valores de $\Delta \widetilde{B}_{X}$ apresentam a pequena sensibilidade da vida típica $B_{X}$, prevista por meio dos ensaios, mediante variação da incerteza experimental.

Finalmente, a queda de $\Delta \breve{B}_{X}$ e de $\Delta B_{X}$ a partir de $B_{90}$, invertendo a sua tendência de aumento com o aumento da incerteza, está provavelmente ligada às dificuldades típicas de previsões de valores extremos das distribuições (O'CONNOR; NEWTON; BROMLEY, 2004), sendo também influenciada pela assimetria das distribuições empíricas de $B_{X}$ (Figura 6a). As simulações revelam que esta assimetria se acentua com aumento do $B_{X}$ simulado e com a diferença entre $C_{0}$ e $C_{i}$. Contudo, com esta observação não se descarta a possibilidade de que parte deste efeito seja resultado do método de simulação adotado, razão pela qual se aponta para a necessidade de cautela nas simulações de condições extremas da influência da incerteza nos testes de vida acelerados. Essa é uma constatação empírica decorrente do processo de simulação realizado, segundo o método proposto.

\subsection{Impacto da incerteza na vida do produto}

Para avaliar o impacto efetivo da incerteza no projeto do produto, tomemos a informação do fabricante do relé testado que indica uma vida típica $B_{50}$ mínima de $10^{6}$ ciclos até sua falha. Da Tabela 5 estima-se uma vida mediana típica $\hat{B}_{50}$ de 1613547 ciclos até a falha, portanto cerca de $60 \%$ maior do que a vida informada pelo fabricante, revelando a esperada margem de segurança encontrada nas informações técnicas de produtos com qualidade.

A partir disso, num projeto otimizado de produto, baseado em dados confiáveis de testes acelerados de vida, sem incertezas, poder-se-ia pensar em explorar melhor esta margem de segurança nitidamente presente nos resultados.

Contudo, se a incerteza na determinação deste valor for considerada, da Tabela 4 verifica-se a expectativa de variações entre 2,5 e $73,4 \%$ quando $u_{c}$ é variado entre 0,01 A e 0,30 A para uma confiança de $95 \%$.

Para trabalhar com as informações do ensaio acelerado, a conduta óbvia é reduzir do valor estimado de $\hat{B}_{50}$ a variação correspondente à incerteza, que corresponde a reduzi-lo em 1,2\% para condições ótimas e 36,7\% para condições usuais de ensaio, assumindo uma distribuição simétrica para o $B_{50}$ em 5,0 A. Isso representa reduzir a vida do relé em cerca de $2 \times 10^{4}$ operações para a incerteza de $0,01 \mathrm{~A}$ e cerca de $6 \times 10^{5}$ operações para a incerteza de $0,30 \mathrm{~A}$. Isso também corresponde a reduzir a expectativa de vida, mesmo sendo ela superior ao valor nominal informado pelo fabricante. De fato, isso representa perder a vantagem estratégica no desenvolvimento do produto originada do conhecimento da vida mediante ensaios.

Considera-se ainda um segundo caso de determinação de prazos de garantia, no qual a vida típica $\hat{B}_{10}$ é necessária. Neste caso, geralmente os fabricantes não fornecem informações claras sobre a vida do componente, fazendo dos ensaios uma das principais fontes para obtenção de informações. Usando a mesma lógica acima, se observa da Tabela 4 a necessidade de redução entre 0,2 e 5,5\% quando incertezas entre $0,01 \mathrm{~A}$ e $0,30 \mathrm{~A}$ estão presentes, que representa uma redução equivalente dos prazos de garantia do produto com os consequientes impactos de 
mercado e custos.

A observação atenta da Tabela 4 permite concluir sobre o agravamento da questão se a condição normal de uso fosse de 1,0 A, bem como o seu relaxamento se fosse de 7,0 A. Contudo, como já discutido, a própria necessidade de testes acelerados tende a conduzir o problema para o seu lado mais crítico em que $C_{0}$ é mais distante de $C_{\mathrm{i}}$, ou seja, para seu uso na estimativa da vida numa condição normal de uso de 1,0 A neste caso.

Finalmente, é importante frisar que a redução discutida de $\hat{B}_{50}$ ou $\hat{B}_{10}$ é motivada exclusivamente pela dúvida no valor calculado, devida à incerteza, e não efetivamente a erros experimentais, tornando o problema discutido de extrema importância pelos seus impactos técnicos e de custos dos produtos nos quais o relé esteja inserido.

\section{Conclusões}

A partir das discussões precedentes, alguns pontos podem ser destacados sobre o problema estudado, bem como sobre a sua abordagem por meio de métodos não paramétricos e de processos de simulação.

Inicialmente é importante notar que o problema se agrava na medida em cresce a diferença entre os níveis de estresse usados no teste acelerado e a carga na condição normal de uso. Esse aspecto é particularmente importante pelo interesse geral de aumentar ao máximo o nível de estresse usado no teste acelerado de vida, até limites tecnicamente admissíveis para o componente, buscando assim a abreviação máxima da duração dos testes dentro do contexto do desenvolvimento de um novo produto (HAHN; MEEKER; DOGANAKSOY, 2003). Por isso, o problema se agrava dentro dos procedimentos usuais adotados para os ensaios acelerados, tornando a questão muito relevante para as condições reais vivenciadas no desenvolvimento de novos produtos.

É interessante observar também que, dependendo do valor da carga em uso normal que define a condição $C_{0}$, a distribuição da vida projetada foge consideravelmente da Normalidade. Nesta situação, geram-se as condições para as quais o método empregado na investigação se mostra adequado. É particularmente importante a estabilidade demonstrada do estimador $\breve{B}_{X}$, obtida com o uso de um grande número de reamostragens no processo de Monte Carlo, apresentando a possibilidade de obter um estimador robusto mesmo na presença de diferentes valores de incerteza.

Os mesmos motivadores para o uso de estatísticas não paramétricas na determinação da vida apontam para a necessidade de maiores investigações sobre o efeito das incertezas nos modelos de relacionamento, aspecto este não considerado nos software comerciais usados em cálculos de confiabilidade.

Finalmente, torna-se claro o impacto mercadológico do problema para o fabricante, por impor reduções nas características de qualidade do seu produto exclusivamente pela incerteza na definição das cargas de ensaios, sendo esta a motivação primeira para o tratamento cuidadoso deste problema no contexto do desenvolvimento do produto.

\title{
Analysis of experimental uncertainties on life determination using accelerated life testing
}

\begin{abstract}
Reliability and accelerated life testing have been increasingly used by companies due to their importance in product development. Accelerated life testing involves activating products under defined conditions and evaluating the probability of their survival after a defined life time, usually called mission, which is closely related to product's warranty. Usually, the stress loads are set at nominal values during accelerated testing procedures. Therefore, accelerated test procedures do not account for either the actual experimental uncertainties related to experimental test conditions or their influences on test results. In this work, actual accelerated life testing data and Monte Carlo simulation methods are used to illustrate the impact of experimental uncertainties on the predicted life of relays under normal conditions and on its management during product design. Results show that the uncertain influences on accelerated life testing can be significant, showing therefore their relevance both on product design and on the definition of warranty periods.
\end{abstract}

Keywords: Product development. Accelerated life testing. Reliability. Uncertainty. 
FORBES, A. B. Least-square best-fit geometric elements. DITC 140/89 Teddington - Middlesex - UK: National Physical Laboratory - NPL, 1989. 30 p. (NPL Report).

HAHN, G. J.; MEEKER, W. Q.; DOGANAKSOY, N. Speedier reliability analysis. Quality progress, Milwaukee - WI, v. 36, n. 6, p. 58-64, 2003.

INTERNATIONAL ORGANIZATION FOR STANDARDIZATION. Guide to the Expression of Uncertainty in Measurement (GUM). Geneva, Switzerland: ISO, 1995. 96 p. (Corrected and Reprinted).

KENETT, R. S.; ZACKS, S. Modern industrial statistic: Design and Control of Quality and Reliability. Pacific Grove: Duxbury Press, 1998. $621 \mathrm{p}$.

MADU, C. N. Reliability and quality interface. International journal of quality and reliability management, Bradford UK, v. 16, n. 7, p. 691-698, 1999.

MADU, C. N. Strategic value of reliability and maintainability management. International journal of quality and reliability management, Bradford - UK, v. 22, n. 3, p. 317-328, 2005.

MARKESET, T.; KUMAR, U. Design and development of product support and maintenance concepts for industrial systems. Journal of quality and maintenance engineering, Bradford UK, v. 9, n. 4, p. 376-392, 2003.

MOONEY, C. Z. Monte Carlo simulation. Iowa: Sage Publications Inc., 1997. 101 p. (Quantitative applications in the social sciences). West Virginia University - USA.

NELSON, W. B. Accelerated testing: statistical models, test plans, and data analysis. New Jersey: John Wiley \& Sons, 2004. 601 p. (Wiley series in probability and mathematical statistics).

O'CONNOR, P. D. T.; NEWTON, D.; BROMLEY, R. Practical reliability engineering. 4. ed. New Jersey: John Willey, 2004. $513 \mathrm{p}$.
OREAR, J. Least square when both variables have uncertainties. American journal of physics, New York, v. 50, n. 10, p. 912-916, 1982.

PALEROSI, C. A. Custos de garantia. In: PALLEROSI, C. A. Garantia em uso e pós-venda. São Paulo: ReliaSoft Brasil, 2002. Cap. 6, p. 59-66. (Confiabilidade: a quarta dimensão da qualidade).

PRESS, W. H. et al. Numerical recipes in FORTRAN: The Art of Scientific Computing. 2. ed. New York: Cambridge University Press, 1992. $963 \mathrm{p}$.

SASSERON, P. L. Estudo experimental de ensaio acelerado aplicado a relés. 2005. 104 f. Dissertação (Mestrado em Engenharia de Produção) - Programa de Pós-graduação em Engenharia de Produção, Universidade Metodista de Piracicaba - UNIMEP, Santa Bárbara d'Oeste - SP, 2005.

TAN, C. M. Customer-focused build-in reliability: a case study. International Journal of Quality and Reliability Management, Bradford - UK, v. 20, n. 2, p. 378-393, 2003.

US Department of Defense. Designing and developing maintainable products and systems. MIL-HDBK-470A Washington - DC: DoD, 1997. 716 p. (Department of Defense Handbook).

VASSILIOU, P.; METTAS, A. Understanding Accelerated Life - Testing Analysis. In: ANNUAL RELIABILITY AND MAINTAINABILITY SYMPOSIUM, 2002, 2002, Seattle - WA, USA. Proceedings... Tucson: ReliaSoft Corp., 2002. p. 1-13.

WALPOLE, R. E.; MYERS, R. H. Probability and Statistics for Engineers and Scientists. 5. ed. New York: Macmillan Publishing Company, 1993. 730 p.

\section{Sobre os autores}

\section{Alvaro José Abackerli Maria Célia de Oliveira Papa Paulo Augusto Cauchick Miguel}

Curso de Pós-graduação em Engenharia de Produção - PPGEP, Faculdade de Engenharia, Arquitetura e Urbanismo - FEAU, Universidade Metodista de Piracicaba - UNIMEP,

Rodovia Santa Bárbara-Iracemápolis Km 1, CEP 13450-000, Santa Bárbara d'Oeste, SP, Brasil, e-mail: abakerli@unimep.br, mceliamat@yahoo.com.br, pamiguel@unimep.br

\section{Pedro Luiz Sasseron}

Laboratório de Máquinas-Ferramentas, Indústrias Romi S.A., Rodovia SP 304, Km 141,5, CEP 13453-900 Santa Bárbara d'Oeste, SP, Brasil, e-mail: psasseron@romi.com.br 
